\title{
IMPACTO DO EFLUENTE TRATADO DA ESTAÇÃO DE TRATAMENTO DE ESGOTO NA QUALIDADE DE ÁGUA DO RIO DE ITAPETININGA, SP
}

\section{IMPACT OF THE TREATED EFFLUENT FROM SEWAGE TREATMENT STATION ON WATER QUALITY OF ITAPETININGA RIVER, SP}

\author{
Vinícius Mori Válio'; Sâmia Maria Tauk-Tornisielo ${ }^{1 *}$; Eleni \\ Nadai Malagutti ${ }^{1}$; Eduardo Beraldo de Morais ${ }^{2^{*}}$;Francisca de \\ Assis Mattioli Gonçalves ${ }^{1}$; Amanda Lodovico de Alcantara ${ }^{1}$ \\ ${ }^{1 *}$ Centro de Estudos Ambientais, Universidade Estadual Paulista "Julio de Mesquita \\ Filho" Av. 24 A, no 1515 Bela Vista. Rio Claro - SP. seb@rc.unesp.br \\ $2^{2 *}$ Depto de Engenharia Sanitária e Ambiental, Universidade Federal de Mato Grosso, \\ Av. Fernando Correa da Costa, 2367, CEP 78060-900, Cuiabá - MT. \\ ebmorais@ufmt.br
}

\section{RESUMO}

Este estudo analisou o impacto do lançamento de efluentes da estação de tratamento de esgoto (ETE) sobre a qualidade da água do rio Itapetininga, SP, desde que o efluente é descartado no córrego Ponte Alta, um afluente do rio estudado. Os parâmetros, medidos mensalmente durante um ano, foram Escherichia coli (NMP/100 mL), demanda bioquímica de oxigênio (DBO) (mg. $\left.\mathrm{L}^{-1}\right)$,

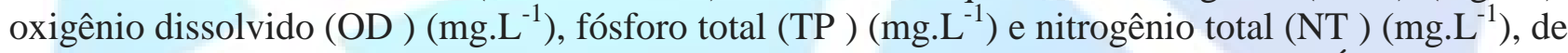
acordo com as metodologias estabelecidas pelo standard Methods para o Exame de Água e Esgoto. Os valores de $E$. coli variaram entre $385,0 \pm 411,0$ e 50.650,0 $\pm 27.477,0$, sendo que os maiores valores no rio Itapetininga foram encontrados após receber as águas do córrego Ponte Alta. Para DBO os valores encontrados variaram de $19,9 \pm 8,4$ a $10,4 \pm 5,0$ e para OD entre $6,0 \pm 1,5$ e 5,6 \pm 1,0. Os valores determinados de outros fatores estudados demonstraram a necessidade do tratamento de esgoto doméstico no rio em estudo.

Palavras-chave: Escherichia coli. Qualidade da Água. Esgoto Doméstico. Índice da Qualidade da Água.

\footnotetext{
ABSTRACT

This study examined the impact of effluent discharge from sewage treatment plant (STP) on the water quality of the Itapetininga river. Since this effluent stream is discarded in Ponte Alta stream, a tributary of the river studied. The parameters measured, monthly during one year, were Escherichia coli (NMP/100 mL), biochemical oxygen demand (BOD) $\left(\mathrm{mg} \mathrm{L}^{-1}\right)$, dissolved oxygen (DO) $\left(\mathrm{mg} \mathrm{L}^{-}\right.$ $\left.{ }^{1}\right)$, total phosphorus (TP) $\left(\mathrm{mg} \mathrm{L}^{-1}\right)$ and total nitrogen $(\mathrm{TN})\left(\mathrm{mg} \mathrm{L}^{-1}\right)$, in accordance with methodologies set out by Standard Methods for the Water and Wastewater Exam. The values of $E$ coli ranged between $385.0 \pm 411.0$ and 50,650.0 \pm 27,477.0, and the highest values were found in
} 
the river Itapetininga after receiving the waters of the stream Ponte Alta. For BOD values ranged from $19.9 \pm 8.4$ to $10.4 \pm 5.0$ and OD between $6.0 \pm 1.0$ and $5.6 \pm 1.5$. The determination of the values of the other elements studied showed the need for treatment of domestic sewage in the river under study.

Keywords: Escherichia coli. Water Quality. Domestic Sewage. Index of Water Quality.

\section{INTRODUÇÃO}

O rio Itapetininga, além de importante para os pequenos, médios e grandes agricultores, fornece alimento para as populações de baixa renda que residem nas proximidades de seu curso e é responsável pelo abastecimento público da cidade de Itapetininga, com uma população de aproximadamente 138 mil habitantes (IBGE, 2007). Torna-se importante citar que o município de Itapetininga, o qual dá nome ao rio, 94\% dos domicílios possuem coleta de esgoto e $100 \%$ deste é tratado. A eficiência de remoção de matéria orgânica, no tratamento, é de 77\% (CETESB, 2009).

Apesar do alto índice de coleta e tratamento, a Estação de Tratamento de Esgoto (ETE), responsável por tratar o esgoto gerado pelos habitantes da área urbana de Itapetininga, não possui sistema específico para desinfecção final e para remoção de nutrientes, como fósforo e nitrogênio principalmente, que podem causar eutrofização dos corpos de água.

O rio Itapetininga está com $25 \%$ da área de suas margens (que são Áreas de Preservação Permanente - APPs) desprovidas de mata ciliar (Comunicação pessoal, Fernando Rosa), e em seu leito existem lugares com níveis críticos de assoreamento onde o nível da água não passa de $50 \mathrm{~cm}$. Além disso, o município de Itapetininga teve o maior "Valor adicionado da Agropecuária" no PIB dos municípios paulistas em 2006 (e um dos maiores do país), com o valor de R\$ 224 milhões (SEADE, 2006). De acordo com o guia de Infraestrutura da cidade; Itapetininga possui uma área de $1.767 \mathrm{~km}^{2}$, sendo o terceiro município em extensão territorial do Estado de São Paulo.

Considerando-se a importância do rio Itapetininga e os problemas nele presentes, era imperativo que se iniciasse um estudo para constatar a qualidade de suas águas, considerando que a CETESB só possui um ponto de coleta de água do tipo "rede básica", para fins de monitoramento neste corpo hídrico.

Apesar da importância e dos problemas mencionados, nenhum estudo com o objetivo especifico de avaliar a qualidade das águas dos rios Itapetininga e Turvo fora realizado até o início deste estudo. A necessidade de maior conhecimento e controle das variações temporais e espaciais da qualidade da água dos corpos hídricos levou a definição de índices de qualidade das águas. De acordo com Toledo e Nicolella (2002) "O uso de indicadores de qualidade de água consiste no emprego de variáveis que se correlacionam com as alterações ocorridas na microbacia, sejam estas de origens antrópicas ou naturais".

Este estudo se propôs verificar as questões que envolvem a qualidade da água e as fontes de poluição, pontuais e difusas, nos rios: Itapetininga, Turvo, Pinhal Grande e ribeirão da Ponte Alta, todos pertencentes à UGRHI 14, com o intuito de fornecer informações para a gestão ambiental da área. Os objetivos específicos foram monitorar os fatores que possibilitam verificar a qualidade da água dos corpos hídricos, determinando Escherichia coli (E. coli), pH, demanda bioquímica de oxigênio (DBO), nitrogênio total, fósforo total, resíduo total, temperatura da amostra, oxigênio dissolvido (OD) e turbidez. Verificar as principais fontes poluidoras das águas nos rios estudados e determinar os principais impactos negativos antrópicos, presentes nas bacias do rio Itapetininga e Turvo. Calcular o IQA (Índice de Qualidade da Água). Comparar os dados obtidos com aqueles da legislação ambiental vigente, em especial a Resolução CONAMA no 357, de 07 de março de 2005 (BRASIL, 2005). 


\section{MATERIAL E MÉTODOS}

\subsection{Bacia do Rio Itapetininga}

A Lei Estadual n 7663 de dezembro de 1991 instituiu a Política de Recursos Hídricos e o Sistema Integrado de Gerenciamento de Recursos Hídricos (SIGRH) dividindo o Estado de São Paulo em 22 Unidades de Gerenciamento de Recursos Hídricos (UGRHIs). A divisão do estado nessas unidades esta ilustrada no canto superior direito da Figura 1. Os rios aqui estudados se encontram na Unidade de Gerenciamento de Recursos Hídricos do Alto Paranapanema, UGRHI 14, destacada e ampliada nesta mesma figura. Os pontos em vermelho marcados em alguns corpos hídricos da Figura 1 foram locais de coleta para a análise de água pela CETESB no ano de 2004.

A UGRHI 14, que corresponde a Bacia Hidrográfica do Alto Paranapanema está localizada no sudoeste do estado de São Paulo e é subdividida em 16 sub-bacias de drenagem hidrográficas. As principais culturas presentes nessa área são as de batata, cana-de-açúcar, feijão, milho, soja e trigo (CBH-ALPA, 1999). Esta Unidade compreende o maior território entre as UGRHIs do Estado de São Paulo e abriga pouco menos de $2 \%$ da população paulista, distribuída em 34 municípios. Nessa UGRHI são coletados $93 \%$ do esgoto produzido e o índice de tratamento é da ordem de $77 \%$ do total do esgoto gerado (CETESB, 2009).

O rio Turvo nasce no município de Piedade-SP, na serra da Queimada, a 1120 metros de altitude e tem $97 \mathrm{~km}$ de extensão (MORAES, 2010). Atravessa áreas dos municípios de Piedade, Tapiraí e Pilar do Sul, onde recebe as águas do rio Pinhal Grande e passa a se chamar rio Itapetininga. Já com este nome, percorre $212 \mathrm{~km}$, passando pelos municípios de Pilar do Sul, Itapetininga e Campina do Monte Alegre, onde deságua no rio Paranapanema.

O rio Itapetininga possui 62 afluentes, dentre os quais se destacam o Ribeirão Laranja Azeda, o Ribeirão Pinhal, Ribeirão dos Macacos, Rio Capivari, Ribeirão Ponte Alta, formado pelas águas dos ribeirões do Chá e dos Cavalos, que margeiam toda a cidade de Itapetininga (AEBRI, 2010), e também os Ribeirões: Grande, da Estiva, da Cachaça, da Pescaria, Cercadinho e São Roque (IHGGI, 2010).

A Figura 2 demonstra a Região de Itapetininga e municípios próximos, destacando-se o rio Itapetininga em cor azul escuro. As sub-bacias de drenagem do Baixo e Alto Itapetininga foram realçadas pelo fundo de cor azul claro e todos os corpos hídricos pertencentes a essas duas subbacias tiveram sua espessura aumentada (inclusive o rio Itapetininga) em relação aos outros corpos hídricos do mapa.

\subsection{Amostragem de águas no rio Itapetininga e afluentes.}

Os pontos de coleta das amostras de água estão representados por quadrados vermelhos ao longo do leito do rio, seguidos de seus respectivos números (Figura 2). Os círculos em amarelo mostram o início e a foz do rio Itapetininga. O quadrado vermelho com o número 7 é o local onde o ribeirão da Ponte Alta deságua no rio Itapetininga. 


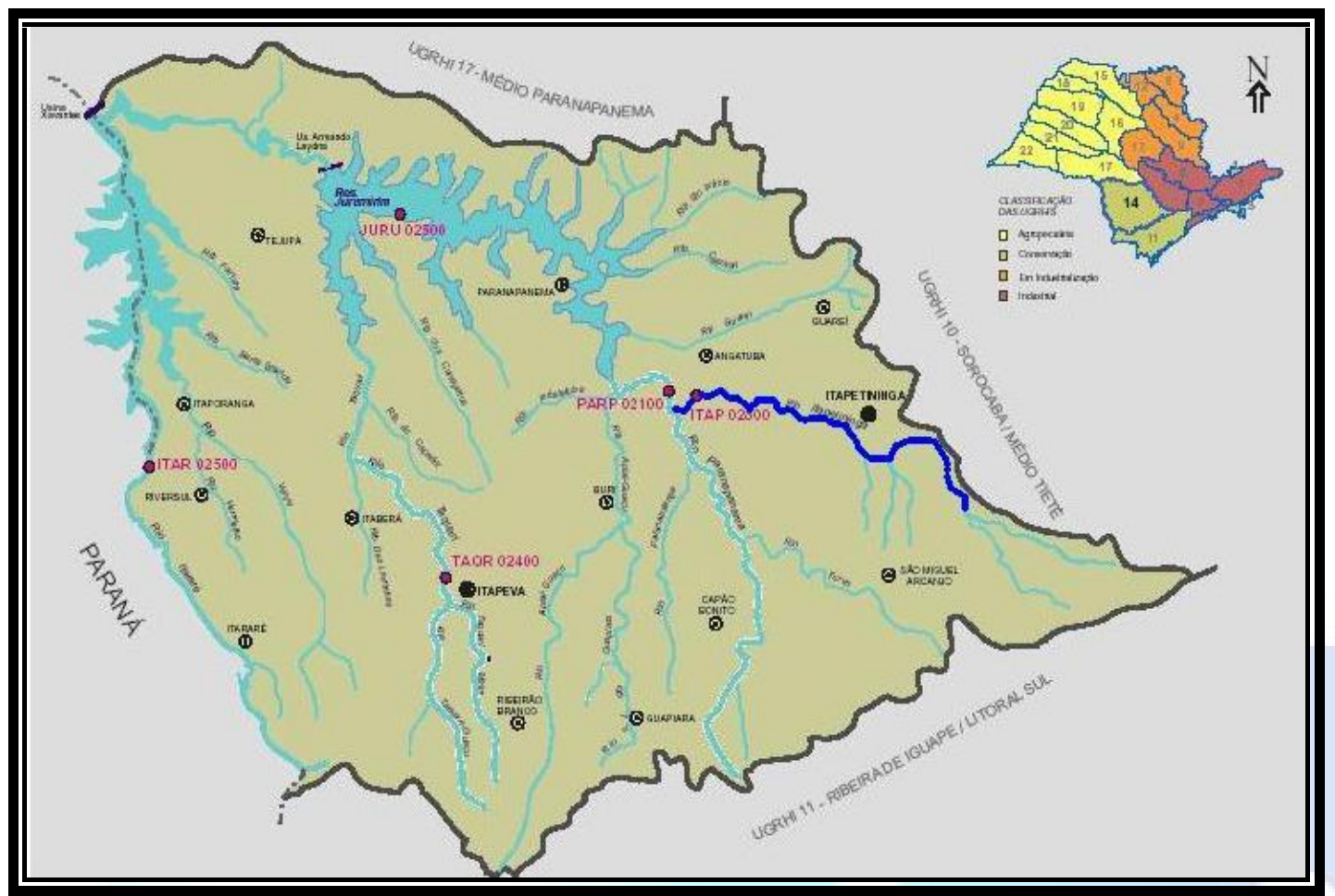

Figura 1. Mapa da Bacia Hidrográfica do Alto Paranapanema. Fonte: (SIRGH, 2009).

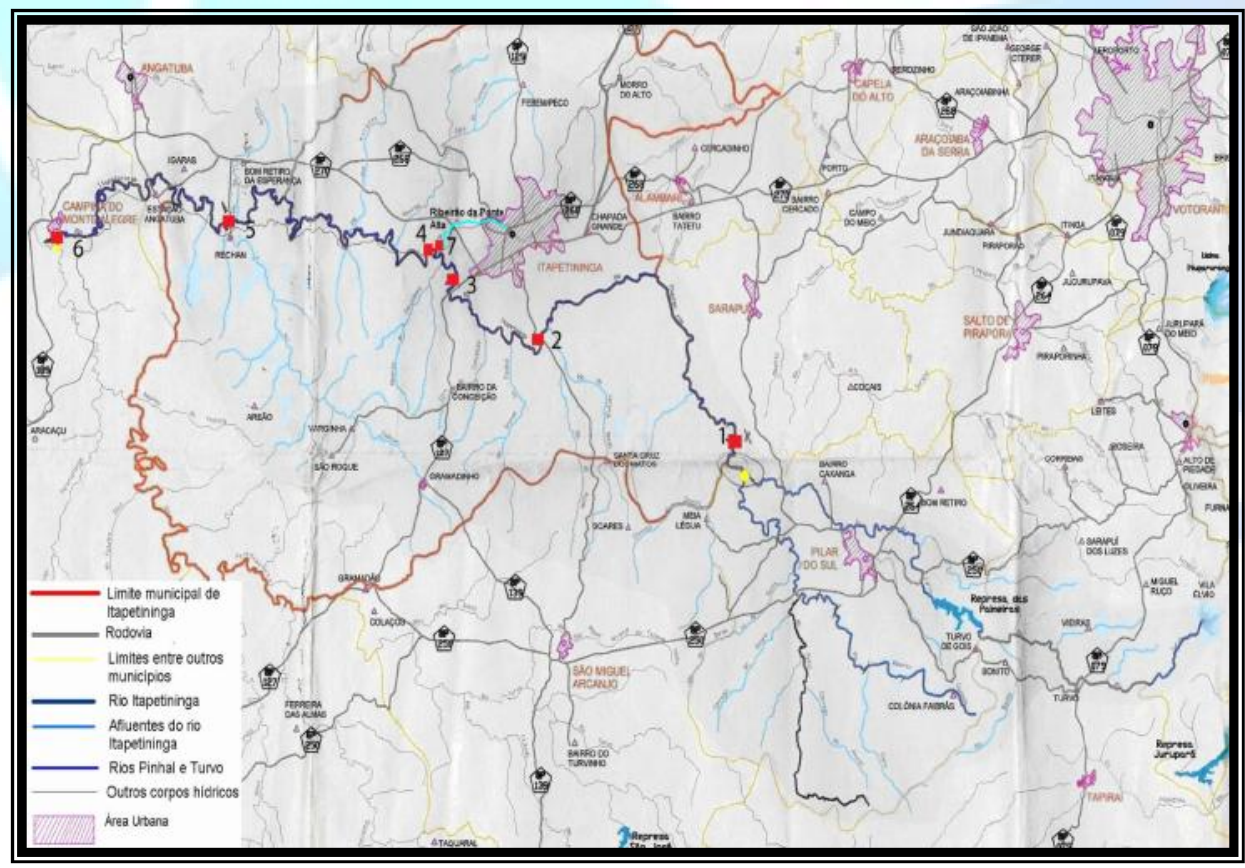

Figura 2. Mapa da Região de Itapetininga e municípios próximos. Fonte: (ROSA, 2009).

No início, o rio Itapetininga apresenta indicadores de poluição, motivando o estudo de seus formadores, especialmente o rio Turvo. Sobre esses é importante mencionar que o rio do Pinhal é basicamente rural e não recebe efluentes de nenhuma cidade, já o rio Turvo, principal formador do 
rio Itapetininga, recebe os efluentes da Estação de Tratamento de Esgoto (ETE) da cidade de Pilar do Sul, por meio do córrego do Pilar (CETESB, 2009) que é afluente do Turvo, e também da ETE do distrito do Turvo, pertencente à cidade de Tapiraí, fazendo parte da UGRHI 11.

A Figura 3 demonstra a localização dos pontos propostos para coleta de amostras de água no rio Turvo, como aqueles localizados no rio Pinhal Grande. Estes pontos estão representados por quadrados na cor preta junto com a legenda para cada respectivo ponto. O ponto amarelo é o local onde o rio Turvo se junta com o rio Pinhal Grande, recebendo após isto o nome Itapetininga. O quadrado em preto apenas com o número 1 é o primeiro ponto de coleta no rio Itapetininga.

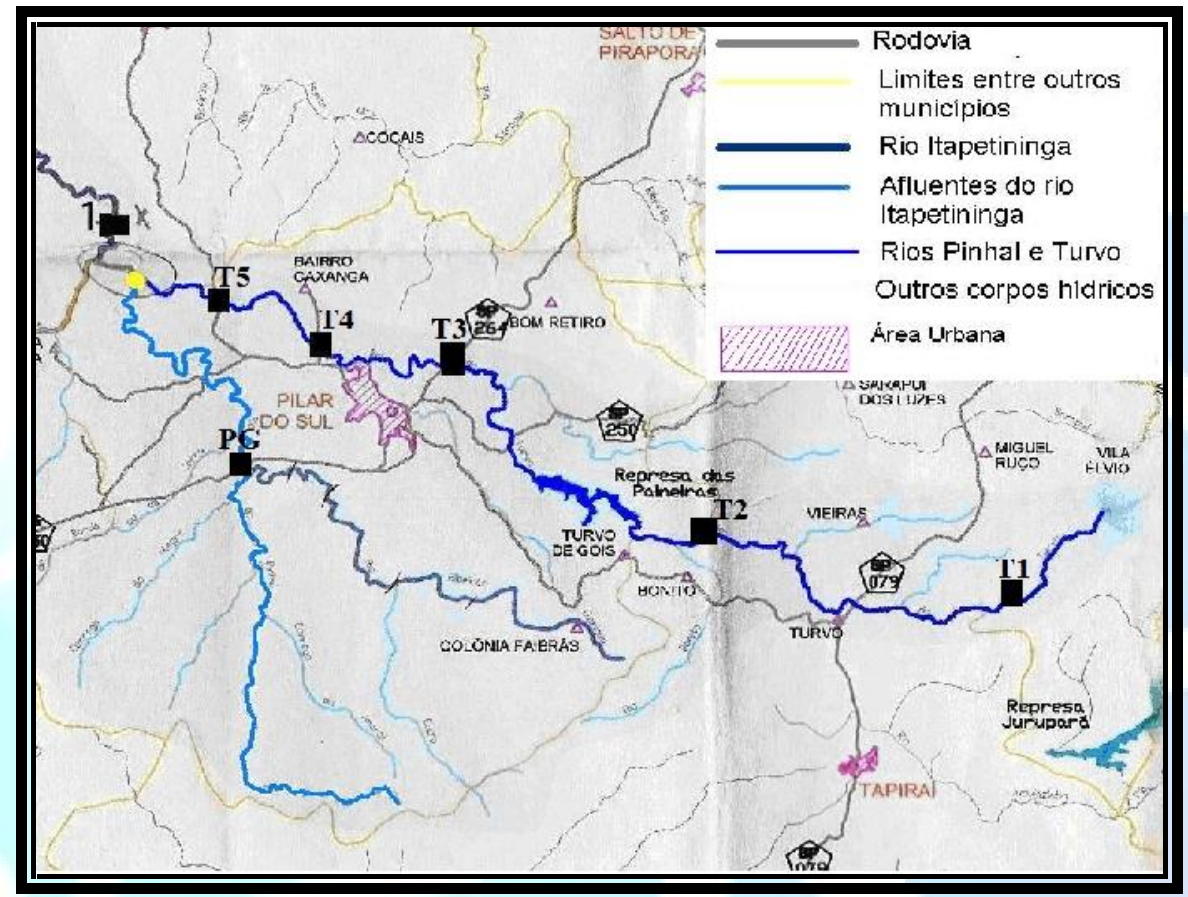

Figura 3. Localização dos pontos de coleta no rio Turvo. Fonte: (ROSA, 2009).

As amostragens realizadas no rio Turvo 1 (T1). Este localizado em uma estrada rural precária, a qual se chega através da rodovia Padre Guilherme Hovel svd (SP-079) e fica a 10 km de distância do distrito do Turvo. Está em uma área montanhosa e com grande quantidade de mata nativa preservada. A altitude é de 880 metros acima do nível do mar, com coordenadas em UTM: 23K, 0251693 L e UTM 7356260 S.

\subsection{Metodologias}

Para cada ponto de coleta foram coletadas 3 amostras de água (duas amostras para análise dos fatores físicos, químicos e fisicoquímicos e a restante para os fatores biológicos) na metade do corte transversal do rio, aproximadamente a $50 \mathrm{~cm}$ de profundidade em relação à superfície da água, com auxílio de amostradores de Van Dorn. Para as análises biológicas foram utilizados frascos previamente esterilizados, fechados e com a tampa envolta por papel protetor.

Após as coletas de amostras de água, os frascos com as mesmas eram acondicionados em caixas térmicas e encaminhados para o laboratório para a realização das devidas análises. Nas Tabelas 1 e 2 se encontram os fatores biológicos, químicos e físicos que serão determinados nas amostras de água, juntamente com suas respectivas metodologias. 
Tabela 1 - Metodologias, equipamentos e referências utilizados para as análises dos fatores biológicos das amostras das águas.

\begin{tabular}{|c|c|c|c|}
\hline \multicolumn{4}{|c|}{ Fatores Biológicos } \\
\hline \multicolumn{2}{|l|}{ Variáveis } & Métodos & Referências e equipamentos \\
\hline $\begin{array}{l}\text { Coliformes } \quad \text { totais } \\
\text { Escherichia coli }(\mathrm{NMP})\end{array}$ & $\mathrm{e}$ & Colilert & APHA (1998) \\
\hline $\begin{array}{l}\text { Demanda bioquímica } \\
\text { oxigênio }\left(\mathrm{DBO}_{5}\right)\left(\mathrm{mg}^{-\mathrm{L}^{-1}}\right)\end{array}$ & $\mathrm{de}$ & Incubação/Winkler & APHA (1998) \\
\hline
\end{tabular}

\subsection{Legislação vigente}

Os corpos hídricos aqui estudados podem ser classificados de acordo com a resolução CONAMA no 357 de 2005 (BRASIL, 2005) e com o decreto Estadual no 8648 de 1976 (SÃO PAULO, 1976). A resolução CONAMA, porém, é mais completa e rígida no que diz respeito à definição e ao estabelecimento dos valores máximos ou mínimos permitidos para os fatores constituintes do IQA, de acordo com a classe dos corpos hídricos. Isso está demonstrado na tabela 3 a seguir, que compara os limites (quando existentes na legislação) estabelecidos pelas duas legislações, federal e estadual, citadas acima, para os fatores constituintes do IQA.

Tabela 2 - Metodologias, equipamentos e referências utilizados para as análises dos fatores físicos, fisicoquímicos e químicos das amostras das águas.

\begin{tabular}{|c|c|c|}
\hline \multicolumn{3}{|c|}{ Fatores Físicos, Químicos e Físico-químicos. } \\
\hline Variáveis & Métodos & Referências e equipamentos \\
\hline Temperatura da água $\left({ }^{\circ} \mathrm{C}\right)$ & $\begin{array}{l}\text { Método automatizado - leitura } \\
\text { direta }\end{array}$ & Termistor - Horiba \\
\hline $\mathrm{Ph}$ & $\begin{array}{l}\text { Método automatizado - leitura } \\
\text { direta }\end{array}$ & Potenciométrica - Horiba \\
\hline Oxigênio dissolvido (mg. $\left.\mathrm{L}^{-1}\right)$ & $\begin{array}{l}\text { Método automatizado - leitura } \\
\text { direta }\end{array}$ & Oxímetro - Horiba \\
\hline Turbidez (UNT) & $\begin{array}{l}\text { Método automatizado - leitura } \\
\text { direta }\end{array}$ & Turbidímetro - Horiba \\
\hline $\begin{array}{l}\text { Sólidos totais dissolvidos - } \\
\text { resíduo total }\left(\mathrm{mg} \cdot \mathrm{L}^{-1}\right)\end{array}$ & $\begin{array}{l}\text { Método automatizado - leitura } \\
\text { direta }\end{array}$ & Horiba \\
\hline Nitrogênio total (mg. $\left.\mathrm{L}^{-1}\right)$ & $\begin{array}{l}\text { Espectrofotométrica- } \\
\text { colorimétrica }\end{array}$ & Golterman et al. (1978) \\
\hline Fósforo total (ug.L ${ }^{-1}$ ) & $\begin{array}{l}\text { Espectrofotométrica- } \\
\text { colorimétrica }\end{array}$ & APHA (1998) \\
\hline
\end{tabular}

Conclui-se que ao atender a resolução CONAMA 357/2005, o decreto Estadual 8468/1976 também será atendido, por este motivo e pelo que foi exposto anteriormente a discussão será embasada somente na resolução CONAMA nº 357 de 2005 (BRASIL, 2005). 
Tabela 3 - Limites estabelecidos por cada legislação para fatores de qualidade da água.

\begin{tabular}{|l|l|c|c|c|c|}
\hline Fator & Legislação & Classe 1 & Classe 2 & Classe 3 & Classe 4 \\
\hline \multirow{2}{*}{ Oxigênio dissolvido $\left(\mathrm{mg}^{-1} \mathrm{~L}^{-1}\right)$} & Federal & 6,0 & 5,0 & 4,0 & 2,0 \\
\cline { 2 - 6 } & Estadual & $*$ & 5,0 & 4,0 & 0,5 \\
\hline \multirow{2}{*}{$\begin{array}{l}\text { Escherichia coli } \\
(\mathrm{NMP} / 100 \mathrm{~mL})\end{array}$} & Federal & 200 & 1000 & 2500 & - \\
\cline { 2 - 6 } & Estadual & $*$ & 1000 & 4000 & - \\
\hline \multirow{2}{*}{ D.B.O (mg.L $\left.{ }^{-1}\right)$} & Federal & 3,0 & 5,0 & 10,0 & - \\
\cline { 2 - 6 } & Estadual & $*$ & 5,0 & 10,0 & - \\
\hline \multirow{2}{*}{ Turbidez (UNT) } & Federal & 40 & 100 & 100 & - \\
\cline { 2 - 6 } & Estadual & - & - & - & - \\
\hline \multirow{2}{*}{ pH } & Federal & 6,0 a 9,0 & 6,0 a 9,0 & 6,0 a 9,0 & 6,0 a 9,0 \\
\cline { 2 - 6 } & Estadual & - & - & - & - \\
\hline \multirow{2}{*}{ Fósforo Total } & Federal & 100 & 100 & 150 & - \\
\cline { 2 - 6 } & Estadual & - & - & - & - \\
\hline
\end{tabular}

\section{RESULTADOS E DISCUSSÃO}

\subsection{Qualidade das Águas do Rio Turvo}

As condições climáticas nos dias das coletas foram em 31/03/2011 chuvoso, 26/05/2011 nublado e em 05/08/2011 frio. Nos três pontos de coletas no Rio Turvo, a $\mathrm{DBO}_{5,20}\left(\mathrm{mg}_{\mathrm{L}} \mathrm{L}^{-1}\right)$ variou entre 4,9 a 12,6; E. coli (NMP/100mL) entre 10,0 e 9139,0; Turbidez (UNT) de 5,0 a 22,0; $\mathrm{pH}$ de 5,5 a 6,3 ; temperatura $\left({ }^{\circ} \mathrm{C}\right)$ de 10,9 a 23,1 ; OD $\left(\mathrm{mg} \mathrm{L}^{-1}\right)$ de 7,4 a 13,4 ; fósforo total $\left(\mu \mathrm{g} . \mathrm{L}^{-1}\right)$ de 53,0 a 308,0; nitrogênio total (mg.L $\left.{ }^{-1}\right)$ de 0,4 a 0,7 e resíduo total $\left(\mathrm{mg} . \mathrm{L}^{-1}\right)$ de 19,0 a 49,0.

Nas amostras coletadas no período seco/frio verificaram-se os menores valores da temperatura da água e de $E$. coli, sendo que no ponto próximo a nascente, geralmente foram observados os mais baixos para $E$. coli no rio Turvo. Os maiores valores foram encontrados nos pontos a jusante de uma pequena ETE, que descarta seu efluente neste mesmo rio.. O maior valor observado foi no ponto após a junção do ribeirão do Pilar, este recebe o efluente final da ETE na cidade de Pilar. Neste ponto o valor deste fator foi $18.350 \mathrm{NMP} / 100 \mathrm{~mL}$ e na segunda coleta foi de 2060 NMP/100 mL, ambos acima do limite máximo estabelecido (1000 NMP/100 mL) para rios de classe 2, de acordo com a Resolução CONAMA 357 de 2005 (BRASIL, 2005).

Quanto aos valores de DBO nas amostras de água nos diferentes pontos de coleta no rio Turvo excederam ao limite estabelecido pela Resolução CONAMA no 357 de 2005 (BRASIL, 2005), ou seja, $10 \mathrm{mg} . \mathrm{L}^{-1}$ (Tabela 8). Os valores elevados, provavelmente, foram consequências da chuva que ocorreu anteriormente as coletas, provocando o deflúvio superficial, portanto, maior aporte de matéria orgânica nas águas do rio Turvo. Estes resultados nem sempre foram observados, como no caso da terceira coleta.

Os valores de DBO obtidos no rio Itapetininga no período chuvoso foram maiores do que aqueles encontrados no rio Turvo. Isto poderá estar relacionado à menor conservação das Áreas de Proteção Permanente (APP) ripárias no rio Itapetininga, da menor quantidade de Reservas Legais nas propriedades rurais e à intensiva e diversificada atividade agrícola na bacia hidrográfica do rio Itapetininga.

Estas características acima citadas podem estar resultando em um maior aporte de sedimentos nos corpos hídricos. A taxa de erosão, e consequentemente de material lixiviado, varia de acordo com o uso do solo (muito maior para qualquer uso agrícola do que se comparado com a presença de vegetação nativa), com a preservação de matas ciliares, e com a quantidade de vegetação nativa na bacia hidrográfica. Pode ser considerado ainda o carreamento de material das propriedades rurais pequenas que usam fossas e de dejetos de animais domésticos e selvagens, como por exemplo, as capivaras. 
Todos os valores obtidos para OD estiveram acima de 6,0 mg.L $\mathrm{L}^{-1}\left(7,0-13,4 \mathrm{mg} . \mathrm{L}^{-1}\right)$, valor mínimo exigido pela Resolução no 357 de 2005 (BRASIL, 2005), para rios de classe 1. Em uma das coletas, a amostra de água analisada estava saturada de oxigênio, devido a uma queda de água localizada dezenas de metros a montante do ponto de coleta. Ao longo da cava principal do rio Turvo até sua foz, os valores de OD foram também decrescendo.

De acordo com Von Speerling (2005), o coeficiente de reaeração de um rio $\left(\mathrm{K}_{2}\right)$, presente na equação de Streeter-Phelps, depende de vários fatores, entre eles a velocidade do corpo hídrico, a qual por sua vez depende também da declividade média do rio. Esta declividade foi calculada e foram encontrados diferentes valores nos trechos estudados. A declividade média para o trecho entre os pontos T2 e T3, por exemplo, foi de $4,36 \mathrm{~m} / \mathrm{Km}$, já entre T5 até a junção com o rio Pinhal Grande foi igual a $0,29 \mathrm{~m} / \mathrm{Km}$. De modo que a capacidade de autodepuração do rio Turvo poderá diferir de acordo com o trecho estudado.

Os valores de $\mathrm{pH}$ encontrados foram todos menores do que 7,0, sendo que o maior valor obtido foi de 6,4 no ponto T5, nas segunda e terceira coletas. Já o menor valor foi de 5,3 no rio Pinhal Grande, seguido do ponto T1 com 5,5, ambos na primeira coleta. Este último apresentou todos os valores abaixo de 6,0 e teve a menor média para este fator; 5,7. Os valores obtidos neste rio foram menores do que aqueles encontrados no rio Itapetininga, o qual, entretanto, também apresentou valores ácidos. Os valores de $\mathrm{pH}$ abaixo de 7,0 encontrados são, provavelmente, resultados das características pedológicas da bacia do rio Turvo, com presença de solos ácidos que reagem com a água conferindo um $\mathrm{pH}$ ácido.

Os valores encontrados de temperatura da água ficaram próximos ao esperado, ou seja, temperaturas mais altas no período chuvoso/quente e mais baixas no período seco/frio. A temperatura da água nos diferentes pontos de coletas variou de forma semelhante. O tempo gasto para a realização das coletas, aproximadamente 5 horas, não foi suficiente para que ocorressem grandes alterações na temperatura da água nos pontos amostrados. Talvez o maior calor latente da água contribuísse para que houvesse tal resultado aqui encontrado, devido à água ter maior resistência às mudanças de temperatura do que o ar.

Os maiores valores de turbidez foram obtidos na primeira coleta (devido à chuva que ocorreu durante a noite anterior), ainda assim, apenas no ponto T5 a turbidez foi maior do que 40 UNT (Unidades Nefelométricas de Turbidez). Este limite estabelecido para rios de classe 1 na Resolução CONAMA n 357 de 2005 (BRASIL, 2005). Nas demais coletas todos os valores encontrados estiveram abaixo deste limite. Apesar disso, os valores deste fator aumentaram ao longo do curso do rio, de T1 a T5. O despejo dos efluentes finais das Estações de Tratamento de Esgoto (ETEs) do distrito do Turvo e do município de Pilar de Sul podem ter sido responsáveis pelo aumento da turbidez nas águas desse rio, da nascente até sua foz.

Quanto ao fator fósforo total, independentemente da coleta, menores valores foram observados no ponto T1 $\left(30 \mu \mathrm{g} . \mathrm{L}^{-1}\right)$, ocorrendo aumento significativo no ponto T2 $\left(179 \mu \mathrm{g} . \mathrm{L}^{-1}\right)$, provavelmente devido ao lançamento do efluente final da ETE do distrito do Turvo. No ponto T3, ocorreu decaimento do valor $\left(53 \mu \mathrm{g} . \mathrm{L}^{-1}\right)$ e no ponto T4, este valor aumentou novamente $\left(125 \mu \mathrm{g} . \mathrm{L}^{-}\right.$ $\left.{ }^{1}\right)$, provavelmente, devido ao lançamento do efluente final da ETE do município de Pilar do Sul, e terminou no ponto T5 com o valor ainda maior $\left(394 \mu \mathrm{g} . \mathrm{L}^{-1}\right)$. Dos valores de fósforo total, $61 \%$ estiveram acima do limite determinado pela Resolução CONAMA n ${ }^{0}$ 357/2005 (BRASIL, 2005), ou seja, $100 \mu \mathrm{g} . \mathrm{L}^{-1}$ para ambiente lótico e tributários de ambientes intermediários pertencentes à classe 2.

A legislação vigente (BRASIL, 2005), entretanto, estabeleceu que o valor máximo admissível de fósforo total pode ser aumentado devido às condições naturais, ou nos casos de estudos ambientais específicos, considerando também a poluição difusa, comprovem que o novo limite não prejudicará os usos previstos no enquadramento do corpo de água. Além das fontes 
pontuais de poluição já citadas anteriormente, os resultados aqui observados estão relacionados com estas, principalmente no período chuvoso/quente, que possui escoamento superficial mais intenso.

Os maiores valores de nitrogênio total foram observados no ponto T5 $\left(1,26 \mathrm{mg}^{-1} \mathrm{~L}^{-1}\right)$ na primeira coleta e $1,12 \mathrm{mg}$. $\mathrm{L}^{-1}$ na segunda coleta. As médias dos valores deste fator aumentaram do ponto T1 até ponto T5, ou seja do início do rio para sua foz. Assim como no fósforo total, esse aumento está relacionado, provavelmente, às fontes de poluição difusa e ao lançamento dos efluentes finais das ETEs do distrito do Turvo e Pinhal Grande.

O maiores valores de resíduos total foram no ponto T5 $\left(54 \mathrm{mg} . \mathrm{L}^{-1}\right)$, semelhantemente aqueles dos fatores anteriores, pois, os valores cresceram seguindo o curso do rio da montante para jusante.

\subsection{Qualidade das Águas do Rio Itapetininga}

$\mathrm{Na}$ tabela 4 verificam-se as datas e as condições climáticas em cada uma das coletas realizadas. Nas tabelas 5 e 6 estão citados os valores máximos, mínimos e as médias obtidas nos pontos de coleta, dos diferentes fatores aqui estudados. Na avaliação temporal e espacial dos fatores abaixo, foram considerados os valores e condições estabelecidos pela Resolução CONAMA n ${ }^{\circ} .357$ de 2005 (BRASIL, 2005).

Tabela 4 - Data e condição climática no dia das coletas no rio Itapetininga.

\begin{tabular}{|l|l|l|}
\hline \hline Coleta & Data & Condição Climática \\
\hline $1^{\underline{\underline{a}}}$ & $13 / 11 / 2009$ & Ensolarado \\
\hline $2^{\underline{\underline{a}}}$ & $14 / 01 / 2010$ & Nublado \\
\hline $3^{\underline{\underline{a}}}$ & $15 / 03 / 2010$ & Chuvoso com Sol \\
\hline $4^{\underline{\underline{a}}}$ & $10 / 05 / 2010$ & Chuvoso e nublado \\
\hline $5^{\underline{a}}$ & $04 / 08 / 2010$ & Nublado \\
\hline $6^{\underline{a}}$ & $20 / 09 / 2010$ & Parcialmente nublado \\
\hline $7^{\underline{a}}$ & $01 / 02 / 2011$ & Ensolarado \\
\hline $8^{\underline{a}}$ & $09 / 05 / 2011$ & Frio \\
\hline $9^{\underline{a}}$ & $07 / 07 / 2011$ & Seco/Frio \\
\hline
\end{tabular}

Tabela 5 - Valores mínimos, máximos e médias dos fatores de qualidade da água nos pontos P1 a P4, no período estudado.

\begin{tabular}{|c|c|c|c|c|c|c|c|c|}
\hline \multirow[t]{2}{*}{ Pontos de coletas } & \multicolumn{2}{|l|}{ P1 } & \multicolumn{2}{|l|}{ P2 } & \multicolumn{2}{|l|}{$\mathbf{P 3}$} & \multicolumn{2}{|l|}{ P4 } \\
\hline & Min/Max & Média & Min/Max & Média & Min/Max & Média & Min/Max & Média \\
\hline $\mathrm{DBO}_{5,20}\left(\mathrm{mg} \cdot \mathrm{L}^{-1}\right)$ & $0,1 / 17,6$ & 10,8 & $3,9 / 18,3$ & 11,2 & $3,2 / 15,9$ & 9,9 & $2,8 / 15,6$ & 9,2 \\
\hline E. coli $(\mathrm{NMP} / 100 \mathrm{~L}$ & $317 / 3784$ & 1248 & $51 / 2400$ & 528 & $84 / 1130$ & 294 & $2010 / 16640$ & 6636 \\
\hline Turbidez (UNT) & $27,0 / 64,1$ & 38,0 & $25,0 / 63,2$ & 37,0 & $21,2 / 85,4$ & 40,0 & $22,0 / 82,0$ & 440,0 \\
\hline $\mathrm{pH}$ & $5,5,6 / 7,5$ & 6,3 & $5,5 / 7,2$ & 6,2 & $5,6 / 7,2$ & 6,3 & $5,5,5 / 7,3$ & 6,3 \\
\hline Temperatura $\left({ }^{\circ} \mathrm{C}\right)$ & $14,8 / 24,3$ & 20,2 & $14,8 / 26,0$ & 21,2 & $14,9 / 26,7$ & 21,3 & $15,0 / 26,5$ & 21,3 \\
\hline $\mathrm{OD}\left(\mathrm{mg} \cdot \mathrm{L}^{-1}\right)$ & $4,8 / 8,8$ & 6,6 & $4,5 / 8,9$ & 6,5 & $4,0 / 8,8$ & 6,5 & $3,9 / 8,4$ & 6,3 \\
\hline Fósforo total $\left(\mu \mathrm{g} \mathrm{L}^{-1}\right)$ & $83 / 470$ & 228 & $70 / 363$ & 192 & $58 / 390$ & 176 & $99 / 397$ & 218 \\
\hline $\begin{array}{l}\text { Nitrogênio total } \\
\left(\mathrm{mg} \cdot \mathrm{L}^{-1}\right)\end{array}$ & $0,56 / 1,68$ & 0,98 & $0,56 / 1,26$ & 0,79 & $0,42 / 1,96$ & 0,87 & $0,7 / 1,26$ & 0,98 \\
\hline Resíduo total $\left(\mathrm{mg} \cdot \mathrm{L}^{-1}\right)$ & $42 / 90$ & 58 & $29 / 68$ & 51 & $34 / 74$ & 49 & $34 / 87$ & 58 \\
\hline
\end{tabular}

Verificou-se que em todas as coletas houve um aumento no valor de E. coli do ponto P3 para o ponto P4. Já na terceira coleta, este valor aumentou de 318 para 16640 NMP/100 mL, acréscimo 
de 52 vezes e 16 vezes maior do que o limite estabelecido pela resolução CONAMA n ${ }^{\circ}$ 357/05 para rios de classe 2 (BRASIL, 2005). Esse aumento é causado pela junção do ribeirão da Ponte Alta (que recebe o efluente final da ETE - Itapetininga) com o rio Itapetininga entre os pontos P3 e P4.

Os resultados obtidos para $\mathrm{DBO}_{5,20}$ durante as coletas realizadas demonstraram que em três, das nove coletas realizadas, todos os valores obtidos para este fator, nos pontos do rio Itapetininga, estiveram abaixo do limite de $10 \mathrm{mg} . \mathrm{L}^{-1}$, estabelecido pela Resolução CONAMA no 357 de 2005 (BRASIL, 2005) para rios de classe 3.

Na segunda coleta todos os valores de DBO nos pontos de coleta foram maiores do que 10 $\mathrm{mg} . \mathrm{L}^{-1}$, com exceção do ponto $\mathrm{P} 4$, na segunda coleta, com um valor de 5,9 mg. $\mathrm{L}^{-1}$. Estes valores, todavia, não foram compatíveis com aqueles esperados, uma vez que este ponto de coleta está localizado a jusante e a 600 metros da confluência do ribeirão da Ponte Alta, corpo hídrico receptor do efluente final da estação de tratamento de esgotos da área de urbana de Itapetininga (ETE Itapetininga). Com relação às médias obtidas, todas foram maiores do que $10 \mathrm{mg} \cdot \mathrm{L}^{-1}$. A maior foi no ribeirão Ponte Alta, $15,7 \mathrm{mg} . \mathrm{L}^{-1}$, ponto que apresentou também o maior valor encontrado para este fator, $34,4 \mathrm{mg} . \mathrm{L}^{-1}$, na quinta coleta.

Tabela 6 -Valores mínimos, máximos e médias dos fatores de qualidade da água nos pontos P5 a P7, no período estudado.

\begin{tabular}{|c|c|c|c|c|c|c|}
\hline \multirow[t]{2}{*}{ Pontos de coletas } & \multicolumn{2}{|l|}{ P5 } & \multicolumn{2}{|l|}{ P6 } & \multicolumn{2}{|l|}{ P7 } \\
\hline & Min/Max & Média & Min/Max & Média & Min/Max & Média \\
\hline $\mathrm{DBO}_{5,20}\left(\mathrm{mg} \cdot \mathrm{L}^{-1}\right)$ & $4,0 / 18,3$ & 10,7 & $3,6 / 19,8$ & 11,3 & $6,0 / 34,4$ & 15,7 \\
\hline E. coli $(\mathrm{NMP} / 100 \mathrm{~mL})$ & $100 / 6570$ & 2683 & $100 / 3590$ & 1031 & $8230 / 91390$ & 38240 \\
\hline Turbidez (UNT) & $22,0 / 131,5$ & 55,0 & $22,0 / 141,0$ & $\overline{54,0}$ & $19,0 / 110,8$ & 50,0 \\
\hline $\mathrm{pH}$ & $5,7 / 7,4$ & 6,4 & $5,7 / 7,4$ & 6,5 & $6,3 / 7,7$ & 6,6 \\
\hline Temperatura $\left({ }^{\circ} \mathrm{C}\right)$ & $15,5 / 26,9$ & 21,7 & $15,6 / 27,3$ & 21,8 & $14,0 / 25,2$ & 20,4 \\
\hline$\overline{\mathrm{OD}}\left(\mathrm{mg} \cdot \mathrm{L}^{-1}\right)$ & $3,6 / 8,5$ & 6,6 & $4,2 / 8,9$ & 6,6 & 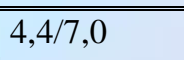 & 5,4 \\
\hline Fósforo total $\left(\mu \mathrm{g} . \mathrm{L}^{-1}\right)$ & $97 / 357$ & 182 & 99/490 & 237 & $161 / 689$ & 374 \\
\hline Nitrogênio total $\left(\mathrm{mg} \cdot \mathrm{L}^{-1}\right)$ & $0,56 / 1,12$ & 0,80 & $0,56 / 0,98$ & 0,74 & $0,56 / 4,76$ & 2,19 \\
\hline Resíduo Total (mg.L $\left.\mathrm{L}^{-1}\right)$ & $48 / 91$ & 62 & $46 / 88$ & 63 & $71 / 148$ & 111 \\
\hline
\end{tabular}

Quanto ao OD, os valores obtidos no rio Itapetininga, quase $30 \%$ estiveram abaixo de 6,0 mg.L ${ }^{-1}$, valor mínimo exigido pela Resolução $n^{\circ} 357$ de 2005 para rios de classe 1 (BRASIL, 2005). Resultados abaixo deste limite foram observados em todos os pontos, na primeira e na segunda coleta, realizadas em novembro de 2009 e janeiro de 2010, respectivamente. Valores de OD abaixo do limite mínimo para rios de classe $2\left(5,0 \mathrm{mg} . \mathrm{L}^{-1}\right)$, porém, foram verificados com frequência média menor.

As médias de OD obtidas para o rio Itapetininga estão em conformidade com a resolução CONAMA no 357/2005 (BRASIL, 2005) para rios de classe 1. Todavia, ao se analisar aquelas determinadas no rio Turvo, seu principal formador, conclui-se que os valores estão paulatinamente diminuindo. A média deste fator passa de 10,8 mg. $\mathrm{L}^{-1}$, em T1, para 6,6 mg.L $\mathrm{L}^{-1} \mathrm{em} \mathrm{P6}$, uma queda que provavelmente é causada por interferências antrópicas.

Valores de $\mathrm{pH}$ abaixo de 6,0, limite mínimo estabelecido pela resolução CONAMA $\mathrm{n}^{\circ}$ 357/2005 (BRASIL, 2005) para rios de qualquer classe, foram encontrados em cinco das nove coletas realizadas. Resultados abaixo deste limite ocorreram em todos os pontos, com exceção de 
P7. Todas as médias obtidas para os pontos de coleta, porém, situaram-se dentro da faixa $(6,0$ a 9,0$)$ estabelecida pela mesma resolução.

No município de Itapetininga há predominância de dois tipos de solos, com incidência de $30 \%$ de cada um. O primeiro é o Latossolo Vermelho-Escuro Orto ("terras vermelhas"), o segundo é o Podzólico Vermelho-Amarelo Orto ("terras de areia") e ambos possuem caráter ácido (IHGGI, 2010). Dessa forma, os valores de $\mathrm{pH}$ abaixo de 7,0 encontrados são provavelmente resultado das condições naturais representadas pelas características pedológicas acima citadas.

Os valores de temperatura da água ficaram próximos ao esperado, ou seja, temperaturas mais altas no período chuvoso/quente e mais baixas no período seco/frio, sendo que a temperatura da água nos diferentes pontos de coletas variou de forma semelhante. As temperaturas observadas no rio Itapetininga foram em média de três graus Celsius acima daquelas observadas no rio Turvo, provavelmente devido à diferença de altitude entre as bacias, à preservação das matas ciliares e diferenças no micro clima.

Durante as outras coletas a variação do valor da turbidez foi menos expressiva, encontrandose entre 30,0 e 60,0 UNT. O limite estabelecido para este fator pela Resolução CONAMA 357/2005 (BRASIL, 2005) para rios de classe 2 é de 100 UNT. Como a turbidez aumentou do primeiro ao último ponto pode-se concluir que além do efeito somatório (de tributários carreando mais partículas e colóides do solo) o efeito da agricultura se torna mais expressivo à medida que o rio segue seu curso (isto pode ser comprovado observando-se fotos de satélite por meio do programa Google Earth). A taxa de erosão varia de acordo com o uso do solo, e é maior para qualquer uso agrícola do que se comparado com a presença de vegetação nativa.

Dos valores de fósforo total, $80 \%$ estiveram acima do preconizado pela Resolução CONAMA 357/2005 (BRASIL, 2005), que estabeleceu o limite de $100 \mu \mathrm{g} . \mathrm{L}^{-1}$ para ambiente lótico e tributários de ambientes intermediários pertencentes à classe 2. Ainda de acordo com a mesma resolução, 64\% dos valores estiveram acima de $150 \mu \mathrm{g} . \mathrm{L}^{-1}$, limite estabelecido para ambiente lótico e tributários de ambientes intermediários pertencentes à classe $3 . \mathrm{O}$ fósforo sozinho, entretanto, deve ser analisado com cautela, pois mesmo sendo usado em grandes quantidades, ele pode ser adsorvido no solo, e aparecer em pequenas concentrações na água. Estes resultados aqui observados estão relacionados com a poluição difusa decorrentes de áreas agrícolas principalmente no período chuvoso/quente, que possui escoamento superficial mais intenso, e com fontes de poluição pontual como o lançamento de esgotos, tratados ou não.

Para o nitrogênio total, maiores valores foram observados no ribeirão da Ponte Alta, 4,2 mg. $\mathrm{L}^{-1}$ na quinta coleta, em agosto de 2010 , e 4,8 mg.. $\mathrm{L}^{-1}$ na última, realizada em julho de 2011 . Este ponto apresentou também a maior média $\left(2,2 \mathrm{mg} \cdot \mathrm{L}^{-1}\right)$, seguida dos pontos $\mathrm{P} 1$ e $\mathrm{P} 4$, ambos com uma concentração média de nitrogênio total igual a 1,0 mg. $\mathrm{L}^{-1}$. Os valores mais altos deste fator no ribeirão da Ponte Alta estão relacionados ao lançamento do efluente final da estação de tratamento de esgoto, ETE-Itapetininga, neste corpo hídrico. Já os valores observados nos pontos P1 e P4 estão relacionados com o despejo do efluente final da ETE do município de Pilar do Sul e com a confluência do ribeirão da Ponte Alta, respectivamente.

\subsection{Cálculo e Avaliação do Índice de Qualidade de Água}

\subsubsection{Valores obtidos para o IQA no rio Turvo}

$\mathrm{Na}$ tabela 7 encontram-se os valores do IQA das águas nos diferentes pontos de coletas de acordo com a classificação adotada pela CETESB (CETESB, 2010). 
Tabela 7 - Valores do IQA de acordo com os pontos e a coleta.

\begin{tabular}{||l||l||l||l||l|l||l||}
\hline \hline Coletas & Ponto T1 & Ponto T2 & Ponto T3 & Ponto T4 & Ponto T5 & Pinhal Grande \\
\hline \hline $1^{\text {a }}$ coleta & 63 & 61 & 70 & 63 & 56 & 65 \\
\hline \hline $2^{\text {a }}$ coleta & 58 & 62 & 65 & 54 & 56 & 65 \\
\hline $3^{\text {a } \text { coleta }}$ & 78 & 64 & 67 & 63 & 68 & 86 \\
\hline Média & $\mathbf{6 6}$ & $\mathbf{6 2}$ & $\mathbf{6 7}$ & $\mathbf{6 0}$ & $\mathbf{6 0}$ & $\mathbf{7 2}$ \\
\hline
\end{tabular}

A qualidade da água foi classificada como "Boa" em todos os IQAs calculados para os pontos do rio Turvo durante as três coletas realizadas. A respeito do ponto próximo a nascente é importante mencionar que durante a segunda coleta houve um número de E. coli igual a 9139 NMP/100mL. Devido ao peso deste fator no cálculo do IQA $(\mathrm{w}=0,12)$, o resultado deste índice foi igual a 58, o que provocou uma queda na média obtida para o índice de qualidade da água. Foi calculado então um IQA hipotético para este ponto na segunda coleta, com todos os valores originalmente obtidos, exceto para $E$. coli, no qual se utilizou uma concentração fictícia de 150 $\mathrm{NMP} / 100 \mathrm{~mL}$, e o resultado deste IQA foi de 71. O qual é coerente com os outros valores obtidos para este ponto. Considerando-se esse resultado, o IQA médio em T1 seria igual a 71.

O rio Pinhal Grande foi o único, durante todo o projeto, a ter a qualidade de suas águas classificada como "Excelente", fato que ocorreu apenas na terceira coleta, com IQA igual a 86. Nas outras duas coletas o valor obtido para este índice foi igual a 65, acarretando uma média igual a 72.

Pode-se concluir que há diminuição na qualidade da água do rio Turvo quando ocorrem lançamentos dos efluentes finais das ETEs do distrito do Turvo e do município de Pilar do Sul, respectivamente. É necessário verificar a qualidade do efluente final dessas duas ETEs, devido à degradação da qualidade da água do rio Turvo após receber o efluente dessas estações. Há necessidade urgente de tratamento do lodo dessas ETEs.

\subsubsection{Valores obtidos para o IQA no rio Itapetininga}

$\mathrm{Na}$ tabela 8 se encontram os valores calculados para o IQA nos pontos constituintes do projeto, da segunda até a nona coleta. As figuras 4 a 11 mostram a qualidade da água, de acordo com a classificação adotada pela CETESB (CETESB, 2010).

Em aproximadamente $10 \%$ dos valores obtidos para os pontos do rio Itapetininga, a qualidade da água foi classificada como "Regular", e nos outros $90 \%$ como "Boa". Dos valores obtidos para o IQA que classificaram como "Boa" a água do rio Itapetininga, 46\%, quase a metade, estiveram entre 52 e 59, ou seja, próximos ao limite (51) para ainda serem classificados nesta categoria. Pode-se afirmar, portanto, que em 52\% dos resultados obtidos, os valores de IQA oscilaram entre 41 e 59.

Tabela 8 - Valores obtidos para o IQA de acordo com os pontos e as coletas, no rio Itapetininga.

\begin{tabular}{|l|c||c|c|c|c|c|c|}
\hline COLETAS & Ponto 1 & Ponto 2 & Ponto 3 & Ponto 7 & Ponto 4 & Ponto 5 & Ponto 6 \\
\hline $2^{\mathbf{a}}$ & 52 & 62 & 55 & 48 & 46 & 47 & 41 \\
\hline $3^{\mathrm{a}}$ & 53 & 55 & 59 & 32 & 44 & 52 & 63 \\
\hline $4^{\mathrm{a}}$ & 54 & 55 & 56 & 44 & 59 & 58 & 53 \\
\hline $5^{\mathrm{a}}$ & 50 & 66 & 65 & 31 & 57 & 59 & 53 \\
\hline $6^{\mathrm{a}}$ & 63 & 69 & 70 & 41 & 54 & 69 & 66 \\
\hline $7^{\mathrm{a}}$ & 57 & 64 & 67 & 50 & 58 & 60 & 67 \\
\hline $8^{\mathrm{a}}$ & 61 & 61 & 64 & 44 & 57 & 58 & 60 \\
\hline \hline $9^{\mathrm{a}}$ coleta & 62 & 66 & 74 & 45 & 63 & 63 & 72 \\
\hline Média & $\mathbf{5 6}$ & $\mathbf{6 2}$ & $\mathbf{6 4}$ & $\mathbf{4 2}$ & $\mathbf{5 5}$ & $\mathbf{5 8}$ & $\mathbf{5 9}$ \\
\hline \hline
\end{tabular}


O ponto P1 teve a qualidade de suas águas classificada como "Regular" apenas na quinta coleta e como "Boa" nas demais, entretanto, em quatro das sete coletas em que a qualidade foi classificada nessa última categoria, os valores estavam próximos ao limite para que a água ainda fosse classificada como "Boa". A média obtida para este ponto foi igual a 56. Os pontos P2 e P3 foram os únicos no rio Itapetininga a ter a qualidade de suas águas classificada como "Boa" em todas as coletas e com quase todos os valores acima de 59 pontos. Já em P4, a qualidade da água foi classificada como "Regular" nas segunda e terceira coletas, e nas demais como "Boa", mas nesse caso, com apenas um valor acima de 59. Os pontos P5 e P6 tiveram a qualidade de suas águas classificadas como "Regular" apenas na segunda coleta, nas demais a qualidade foi classificada como "Boa".

O ribeirão Ponte Alta obteve a menor média, 42, com valores para o IQA oscilando entre 31 e 50. O principal fator que influenciou negativamente o IQA foi a quantidade de E. coli. Tratandose de um dos poucos rios ainda não poluídos do estado de São Paulo, o resultado pode ser considerado alarmante, já que de acordo com a própria Sabesp (2009), infelizmente não existem estudos anteriores com quantidade significativa de pontos de coleta para que os valores obtidos do IQA neste estudo sejam comparados. 

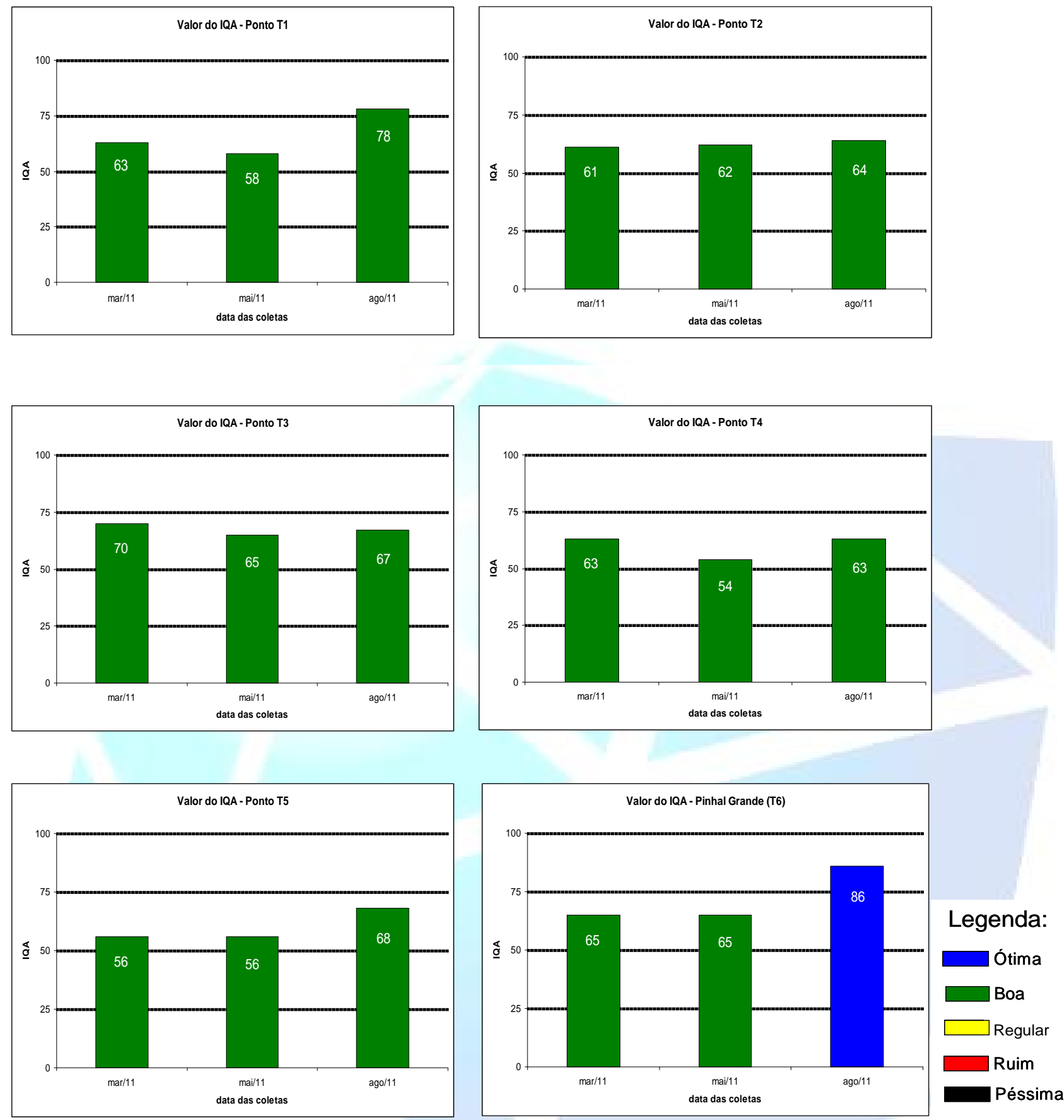

Figura 4. Valores do Índice de Qualidade da Água (IQA) nos diferentes pontos de coletas de amostras de água. 


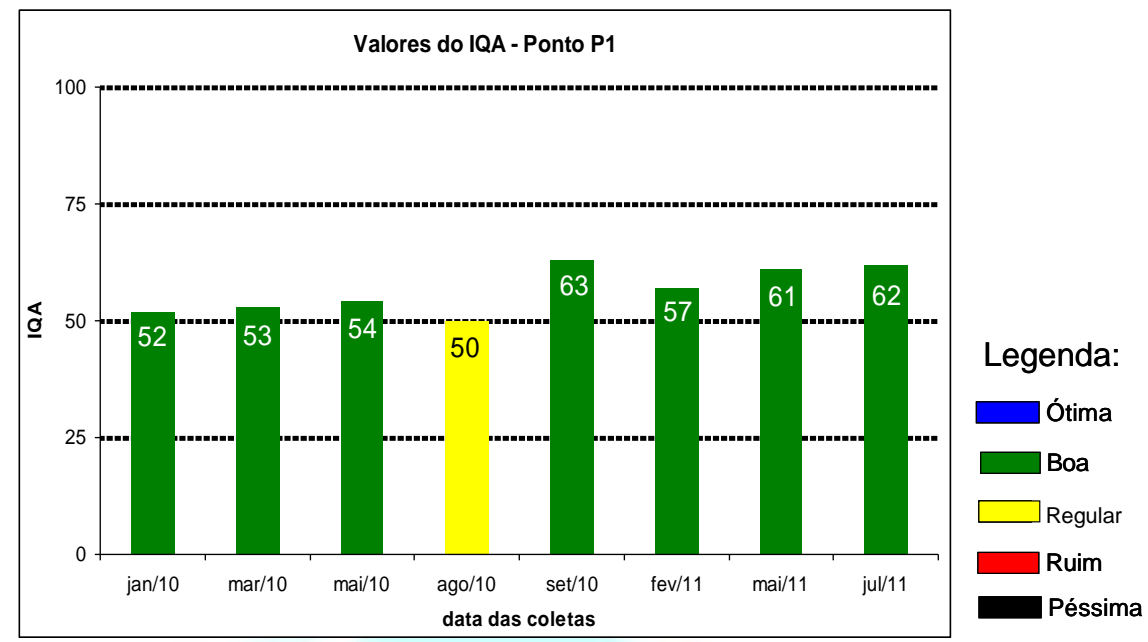

Figura 5. Índice de qualidade da água do ponto P1.

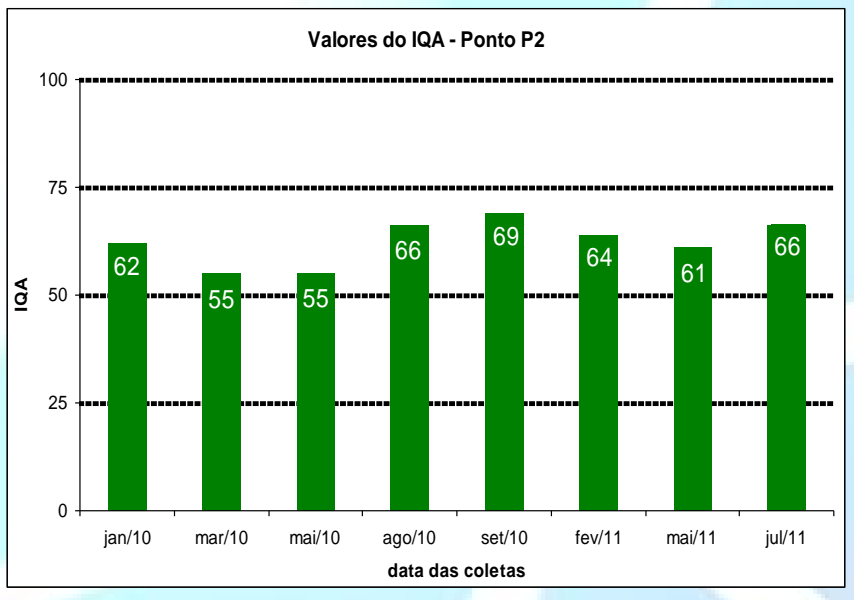

Legenda:

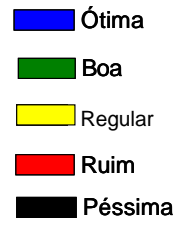

Figura 6. Índice de qualidade da água do ponto P2.

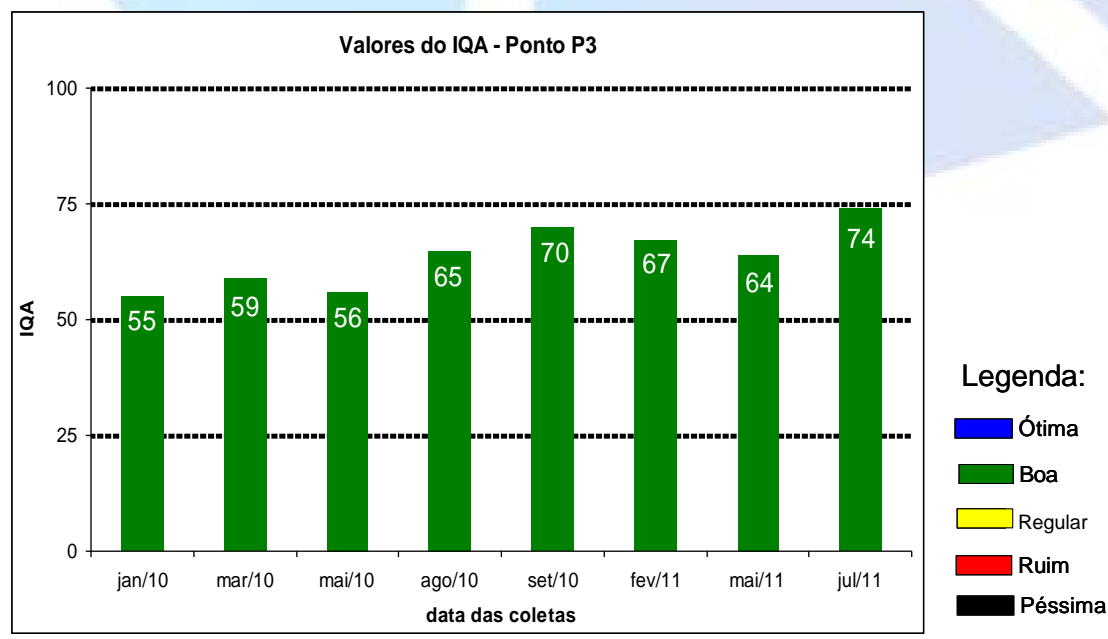

Figura 7. Índice de qualidade da água do ponto P3. 


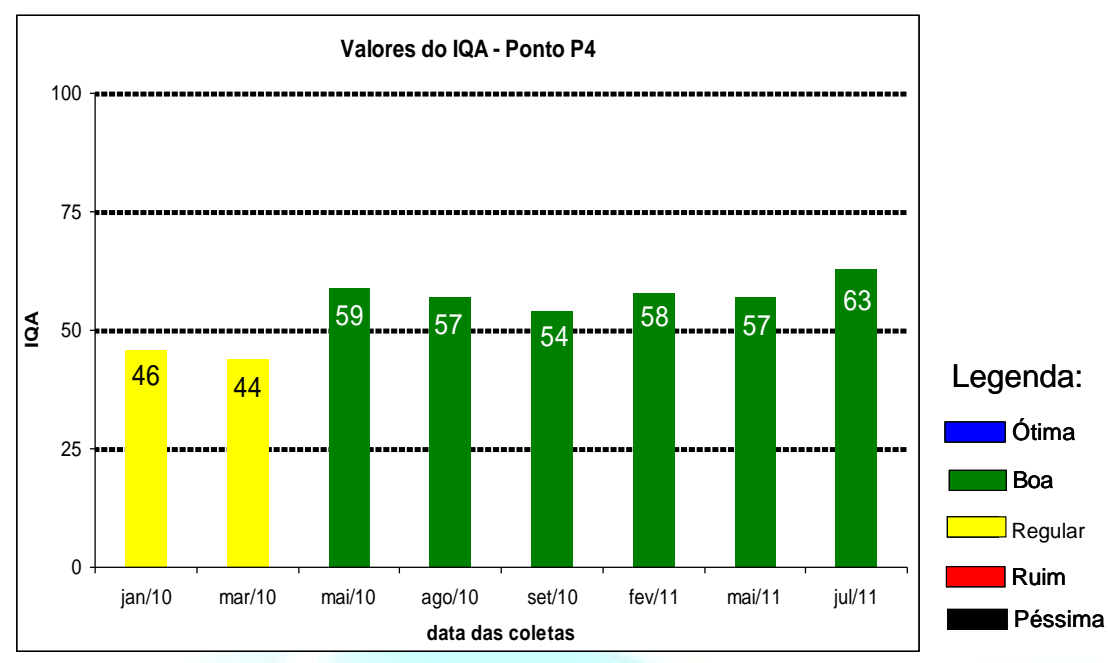

Figura 8. Índice de qualidade da água do ponto P4.

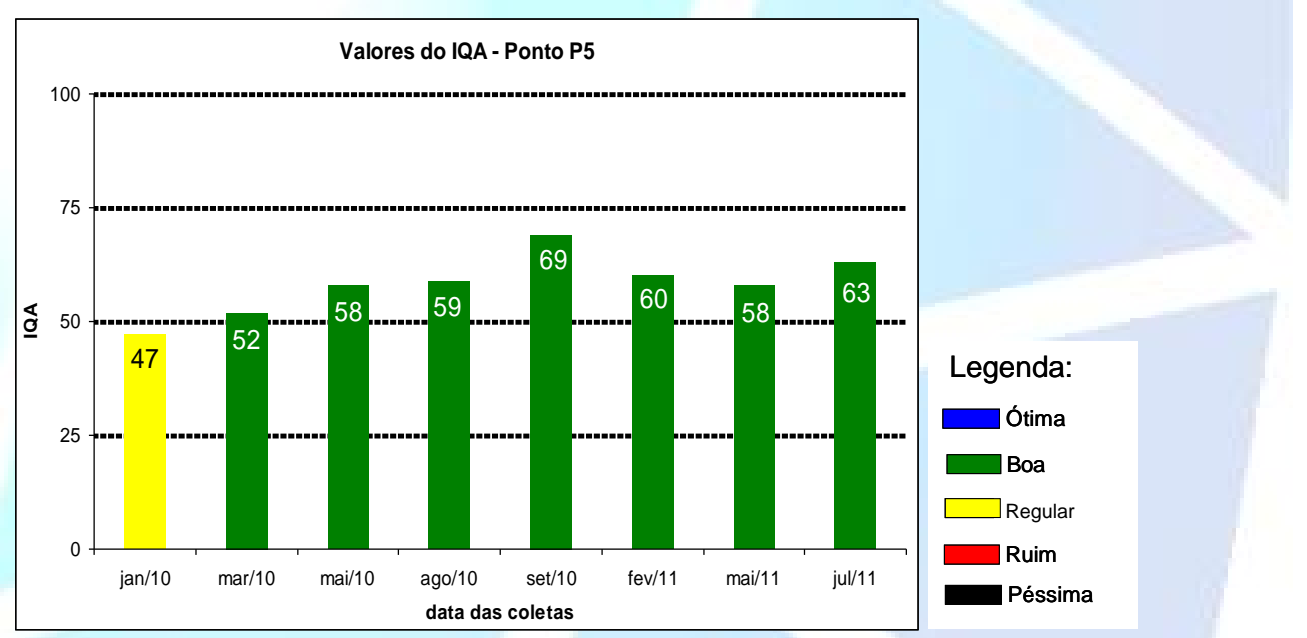

Figura 9. Índice de qualidade da água do ponto P5.

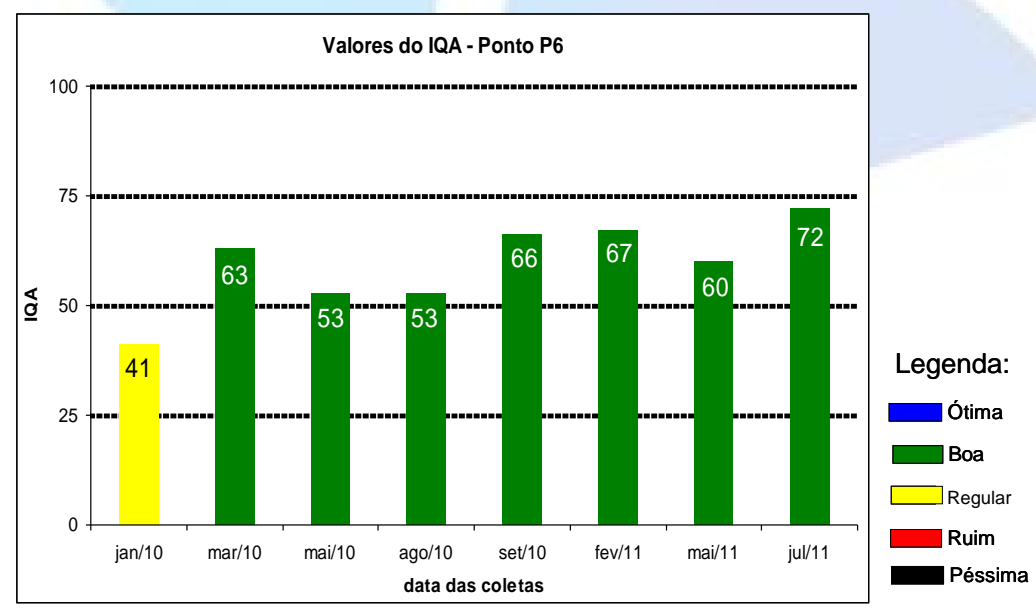

Figura 10. Índice de qualidade da água do ponto P6. 


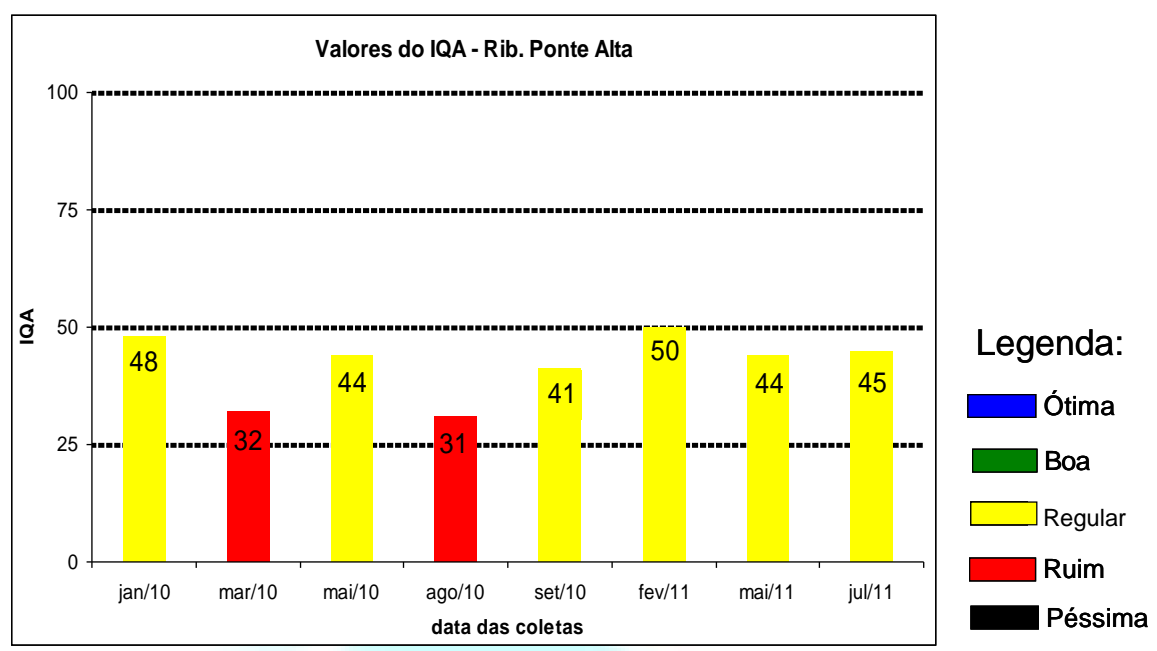

Figura 11. Índice de qualidade da água do ribeirão Ponte Alta (P7).

\subsection{Análise de Metais no Rio Itapetininga}

Nas Tabelas 9 e 10, respectivamente, estão os limites para os metais analisados de acordo com a resolução acima citada, e os resultados obtidos (durante a nona coleta no rio Itapetininga) para os mesmos.

Tabela 9 - Limites estabelecidos para os metais de acordo com a classe do corpo hídrico. Fonte: Adaptado de CONAMA 357/2005 (Brasil, 2005).

\begin{tabular}{|l|l|l|l|l||}
\hline Fatores inorgânicos & Classe 1 & Classe 2 & Classe 3 & Classe 4 \\
\hline Ferro dissolvido $\left(\mathrm{mg} . \mathrm{L}^{-1}\right)$ & 0,3 & 0,3 & 5,0 & - \\
\hline Manganês total $\left(\mathrm{mg} . \mathrm{L}^{-1}\right)$ & 0,1 & 0,1 & 0,5 & - \\
\hline Zinco total $\left(\mathrm{mg} \cdot \mathrm{L}^{-1}\right)$ & 0,18 & 0,18 & 5,0 & - \\
\hline Alumínio dissolvido $\left(\mathrm{mg} . \mathrm{L}^{-1}\right)$ & 0,1 & 0,1 & 0,2 & - \\
\hline Chumbo total $\left(\mathrm{mg} . \mathrm{L}^{-1}\right)$ & 0,01 & 0,01 & 0,033 & - \\
\hline Cromo total $\left(\mathrm{mg} . \mathrm{L}^{-1}\right)$ & 0,05 & 0,05 & 0,05 & - \\
\hline
\end{tabular}

Tabela 10 - Valores obtidos para os metais analisados de acordo com os pontos de coleta no rio Itapetininga.

\begin{tabular}{|l|l|l|l|l|l|l|l||}
\hline Fatores inorgânicos & P1 & P2 & P3 & P4 & P5 & P6 & P7 \\
\hline Ferro dissolvido $\left(\mathrm{mg} . \mathrm{L}^{-1}\right)$ & 0,450 & 0,312 & 0,488 & 0,517 & 0,390 & 0,494 & 0,421 \\
\hline Manganês total $\left(\mathrm{mg} \cdot \mathrm{L}^{-1}\right)$ & 0,053 & 0,046 & 0,054 & 0,061 & 0,053 & 0,043 & 0,111 \\
\hline Zinco total $\left(\mathrm{mg} . \mathrm{L}^{-1}\right)$ & 0,005 & 0,002 & 0,002 & 0,003 & 0,005 & 0,005 & 0,013 \\
\hline Alumínio dissolvido $\left(\mathrm{mg} \cdot \mathrm{L}^{-1}\right)$ & 0,337 & 0,118 & 0,176 & 0,210 & 0,210 & 0,408 & 0,127 \\
\hline Chumbo total $\left(\mathrm{mg} . \mathrm{L}^{-1}\right)$ & $*$ & $*$ & 0,001 & $*$ & $*$ & $*$ & $*$ \\
\hline Cromo total $\left(\mathrm{mg} . \mathrm{L}^{-1}\right)$ & 0,002 & 0,001 & 0,001 & 0,001 & 0,002 & 0,001 & 0,001 \\
\hline
\end{tabular}

Todos os valores obtidos para o cromo total estiveram abaixo do limite $0,05 \mathrm{mg} . \mathrm{L}^{-1}$ estabelecido pela resolução CONAMA no 357/2005 (BRASIL, 2005), para rios das classes 1, 2 ou 3. Estes foram 50 a 25 vezes menores do que o limite acima citado. Para o fator chumbo total os valores encontrados sempre estiveram abaixo do limite permite pela legislação vigente. Resultados semelhantes foram encontrados para manganês total, sendo que as concentrações foram em média, iguais a metade do limite acima citado, diferentemente do que ocorreu com os fatores chumbo total e cromo total. 
Quanto aos valores do fator zinco total estiveram dentro do limite de $0,18 \mathrm{mg} . \mathrm{L}^{-1}$, estabelecido pela resolução citada anteriormente, para rios de classe 2. Este fator apresentou a maior diferença entre os valores obtidos e o limite para o mesmo, sendo que os resultados foram até 90 menores que o limite de $0,18 \mathrm{mg} \cdot \mathrm{L}^{-1}$.

Os fatores alumínio dissolvido e ferro dissolvido foram os únicos a apresentarem resultados não conformes em relação à resolução CONAMA no 357/2005 (BRASIL, 2005). Todas as concentrações obtidas para o ferro dissolvido estiveram acima do limite de $0,3 \mathrm{mg} . \mathrm{L}^{-1}$ estabelecido para rios de classe 2. Os valores destes fatores acima do limite constituíram evidências da erosão das margens e consequente assoreamento do rio Itapetininga, pois estes elementos estão presentes naturalmente no solo, e, como já foi citado anteriormente, em concentrações acima do limite estabelecido podem indicar indiretamente a presença de processos erosivos.

\section{CONCLUSÕES}

O rio Turvo teve a qualidade de suas águas classificada como "Boa", porém com alguns resultados próximos ao limite para ainda serem classificados nesta categoria. As principais fontes pontuais de poluição são os lançamentos dos efluentes finais das ETEs do distrito do Turvo e, a jusante, daquela do município de Pilar do Sul. Assim como no rio Itapetininga, a atividade agrícola também é a principal fonte de poluição difusa no rio Turvo, mas esta não é tão intensa na bacia de drenagem deste corpo hídrico. Este, além disto, possui, relativamente, maior quantidade de matas ciliares preservadas as quais servem como "filtro", diminuindo o aporte de sedimentos e resíduos de fertilizantes e agrotóxicos gerados como consequência da atividade agrícola.

Por meio do IQA observou-se que a qualidade da água do rio Itapetininga é considerada de "Regular" a "Boa". Parte dos impactos causados no rio Turvo chega ao rio Itapetininga, como o despejo do efluente da ETE do município de Pilar do Sul.

Os principais fatores de impacto ambiental no rio Itapetininga são o lançamento do efluente final da ETE-Itapetininga no ribeirão Ponte Alta, que é afluente do primeiro, os processos de erosão e assoreamento, resultado da ausência de matas ciliares em muitos trechos do rio. A agricultura, que é muito expressiva no município de Itapetininga também contribui para o impacto ambiental no rio de mesmo nome, pois se observaram altos valores de nitrogênio total e fósforo total, elementos que podem causar a eutrofização de corpos de água e são provenientes do aporte de fertilizantes químicos ao rio por meio do deflúvio superficial agrícola.

\section{AGRADECIMENTOS}

Agradecemos à FAPESP - pela bolsa de Iniciação Científica, Processo nº 09/52403-6.

\section{REFERÊNCIAS}

AEBRI - ASSOCIAÇÃO ECOLÓGICA DA BACIA DO RIO ITAPETININGA. O Rio. Disponível em: <http://www.aebri.com.br/O\%20Rio.html>. Acesso em: 5 de set. 2010.

APHA - AMERICAN PUBLIC HEALTH ASSOCIATION. Standard methods for the examination of water and wastewater. 20 ed. Washington: American Public Health Association, AWWA, WPCF, 1998. 1569p. 
BRASIL. Ministério do Meio Ambiente. Conselho Nacional do Meio Ambiente. Resoluções do CONAMA 357. ed. Brasília, DF. SEMA, 2005. 23 p.

CBH-ALPA - COMITÊ DA BACIA HIDROGRÁFICA DO ALTO PARANAPANEMA. Minuta Preliminar do Relatório de Situação dos Recursos Hídricos da UGRHI 14. CETEC (Centro Tecnológico da Fundação Paulista de Tecnologia e Educação). Lins, 1999. 318p.

CETESB (a) - COMPANHIA AMBIENTAL DO ESTADO DE SÃO PAULO. Relatório de qualidade das águas interiores do estado de São Paulo 2008. São Paulo, 2009. 531 p.

GOLTERMAN, H.L.; CLYMO, R.S.; OHNSTAND, M.A. Methods for physical and chemical analysis of fresh water. 2.ed. Oxford: Blackwell Scientific Publications, International Biological Program, 1978. 213p. (IPB Handbook, n.8).

IHGGI - INSTITUTO HISTÓRICO, GEOGRÁFICO E GENEALÓGICO DE ITAPETININGA. Geografia. Disponível em: 〈http://www.ihggi.org/>. Acesso em: 05 set. 2010.

MORAES, H. Historiador descobre a nascente do rio Itapetininga e altera a historia vigente. 2010. Disponível em:

<http://jornalrol.com.br/cidadania/index.php?option=com_content\&view=article\&id=234:exc lusivo-pesquisador-ihgg-i-corrige-informacao-sobre-a-nascente-do-rioitapetininga\&catid=7:caso-nardelli\&Itemid=44>. Acesso em: 03 de set. 2010.

ROSA, F. Comunicação pessoal sobre os dados obtidos em estudo feito no projeto Rio Vivo. Itapetininga-SP. 2009.

SEADE - FUNDAÇÃO SISTEMA ESTADUAL DE ANÁLISE DE DADOS. PIB dos Municípios Paulistas, 2006. Disponível em: <http://www.seade.gov.br>. Acesso em: 10 de jan. 2009

SIRGH - SISTEMA INTEGRADO DE GERENCIAMENTO DOS RECURSOS HÍDRICOS. Disponível em: <http://www.sirgh.sp.gov.br>. Acesso em: 17 de abril. 2009

TOLEDO, L.G.; NICOLELLA, G. Índice de qualidade da água em Microbacia sob uso agrícola e urbano. Scientia Agricola, Piracicaba, v.59, n.1, p.181-186, 2002.

VANZELA, L.S., LIMA, R.C., HERNANDEZ, F.B.T., MAURO, F. Diagnóstico da Vazão e Descarga Sólida Total do Córrego Três Barras no Município de Marinópolis - SP. In : Congresso Brasileiro de Engenharia Agrícola, 33, 2004, São Pedro - SP. Anais... SBEA, 2004. p. 4.

VON SPERLING, M. Introdução à qualidade das águas e ao tratamento de esgotos.

3. ed. Belo Horizonte, Departamento de Engenharia Sanitária e Ambiental, Universidade Federal de Minas Gerais, 2005. 243p. 